\title{
PURIFICAÇÃO PARCIAL E CARACTERIZAÇÃO BIOQUÍMICA DE LIPASE EXTRACELULAR PRODUZIDA POR NOVA LINHAGEM DE Rhizopus sp. ${ }^{1}$
}

\author{
Gláucia M. PASTORE ${ }^{2 *}$, Vinicius dos Santos R. da COSTA², Maria Gabriela B. KOBLITZ2
}

\section{RESUMO}

Lipases são enzimas capazes de catalizar uma grande gama de reações de interesse para as indústrias alimentícia, farmacêutica, química, entre outras. Esta versatilidade se deve também às diversas possibilidades de especificidade quanto ao substrato que lipases de diferentes fontes apresentam. Por este motivo, microrganismos produtores desta enzima vêm sendo procurados por grupos de pesquisa no mundo todo. Este trabalho apresenta as propriedades de uma lipase produzida por nova linhagem fúngica de Rhizopus sp. A enzima bruta apresentou condições ótimas de atividade a $40^{\circ} \mathrm{C}$ em valores de $\mathrm{pH}$ entre 6,0 e 6,5 . e manteve $50 \%$ ou mais de sua atividade quando aquecida por 60 minutos à temperaturas entre $40^{\circ} \mathrm{C}$ e $55^{\circ} \mathrm{C}$. A atividade hidrolitica da lipase bruta foi maior quando o substrato testado foi a gordura de coco, demonstrando afinidade por ácidos graxos saturados de cadeia média. As frações I e II obtidas após purificação parcial da enzima apresentaram características bioquímicas semelhantes as do extrato bruto.

Palavras-chave: enzima; lipase; Rhizopus sp.; caracterização bioquímica.
\end{abstract}

\section{SUMMARY}

PRODUCTION, PARTIAL PURIFICATION AND BIOCHEMICAL CHARACTERIZATION OF A NOVELL Rhizopus sp. STRAIN LIPASE. Lipases are enzymes capable of catalyzing a great variety of reactions that are interesting to food, pharmaceutical, chemical, and other industries. This versatility is also due to the different substrate specificity possibilities that lipases from various sources. For this reason, lipase producing microorganisms are being searched by research groups around the world. This paper presents the properties of a extracellular lipase produced by a newly isolated strain of Rhizopus sp. The crude enzyme showed optimal activity at $40^{\circ} \mathrm{C}$, between 6.0 and $6.5 \mathrm{pH}$ values and kept $50 \%$ of it's activity after treatment between $40^{\circ} \mathrm{C}$ and $55^{\circ} \mathrm{C}$ for 60 minutes. The hydrolytic activity of the crude extract was greater when coconut fat was used as substrate. This shows the affinity of the lipase to saturated medium chain fatty acids. The fractions I and II, that were obtained after the partial purification of the lipase, showed biochemical characteristics similar to the crude extract. Keywords: enzyme; lipase; Rhizopus sp.; biochemical characterization.

\section{1 - INTRODUÇÃO}

Lipases são enzimas pertencentes ao grupo das serina hidrolases (E.C. 3.1.1.3). Seus substratos naturais são triglicerídeos e o seu modo de ação se assemelha ao das esterases, porém, sua atividade é muito aumentada quando situada na interface polar/apolar e apresentam maior afinidade por ácidos graxos de cadeia longa. A teoria atualmente mais aceita para este fenômeno diz que uma parte da superficie da enzima se encontra em melhor equilibrio termodinâmico quando inserida na interface polar/apolar e que esta conformação coloca o sítio ativo da enzima em posição favorável para catálise [1]. As lipases são capazes de catalisar reações de hidrólise, esterificação, transesterificação e lactonização (esterificação intramolecular). Esta flexibilidade aliada a diferentes possibilidades de especificidade de substrato existentes entre as diferentes lipases confere a estas enzimas um potencial enorme de aplicações [3]. A Tabela 1 ilustra algumas das possibilidades de uso, em escala industrial, das lipases em diferentes áreas [2, 3, 8, 9, $10,11]$. Além das possibilidades de aplicação na indústria, as lipases estão ligadas à deterioração de alguns produtos, principalmente de laticínios e de óleos comestiveis e a identificação e estudo de seu modo de ação podem auxiliar grandemente na solução destes problemas [5].

1. Recebido para publicação em 11/05/2001. Aceito para publicação em 29/08/2002 (000638).

UNICAMP - FEA - DCA. CX. Postal: 6121. CEP 13083-970, SP. glaupast@fea.unicamp.br

* A quem a correspondência deve ser enviada.
Lipases podem ser encontradas em células de tecidos animais e vegetais e podem ainda ser produzidas por microrganismos. Do ponto de vista industrial estas são consideradas de maior importância devido ao seu maior potencial de produção em larga escala em comparação com outras fontes de lipase [8, 12, 13]. Além disso, microrganismos produtores de lipases podem contaminar alimentos causando grandes prejuizos principalmente à indústria de laticinios e de óleos [5]. Embora os estudos cientificos tenham se concentrado mais na aplicação destas enzimas, alguns grupos de pesquisa se dedicam também ao isolamento de microrganismos produtores de lipases, em busca de novas enzimas com diferentes especificidades de substrato.

TABELA 1. Aplicações industriais das lipases

\begin{tabular}{|c|c|}
\hline Indústrin & Aplicação \\
\hline \multirow[t]{2}{*}{ Latićnio } & Hidrólise da gordura do leite \\
\hline & Aumento do aroma, da qualidade e da vida de prateleira \\
\hline Cervejaria & Aumento do aroma e aceleração do processo fermentativo \\
\hline Mollos e condimentos & Aumento de propriedades funcionais da gema de ovo \\
\hline Processamento de carnes & $\begin{array}{l}\text { Desenvolvimento de aromas e redução no conteúdo de } \\
\text { gorduras }\end{array}$ \\
\hline óleos e gorduras & $\begin{array}{l}\text { Transesterificação de óleos - introdução de ácidos graxos de } \\
\text { interesse em óleos e gorduras naturais }\end{array}$ \\
\hline Química fina & Síntese de ésteres e resolução de racematos \\
\hline Detergentes & Hidrólise de gorduras \\
\hline Farmacêutica & Auxiliares de digestão \\
\hline Médica & Determinação de lipídeos no sangue (biossensores) \\
\hline Couro & Remoção de gor dura da matéria-prima \\
\hline Tratamento de resíduos & Decomposição de lipídeos de efluentes. \\
\hline
\end{tabular}

Fonte: GANDHI (4) 
Este trabalho relata a caracterização de uma lipase extracelular produzida por nova linhagem fúngica de Rhizopus sp., isolada no Laboratório de Bioaromas da Faculdade de Engenharia de Alimentos, UNICAMP, a metodologia para obtenção e purificação parcial desta enzima e a caracterização bioquimica do extrato bruto e das frações obtidas no processo de purificação. A lipase em questão ainda se encontra em estudo para sua purificação total, quanto a sua capacidade de produção de ésteres e quanto a sua enantioseletividade, dados estes que serão publicados oportunamente.

\section{2 - MATERIAL E MÉTODOS}

\section{1 - Produção da enzima}

A nova linhagem de Rhizopus sp foi isolada, juntamente com um grande número de outros microrganismos, de restos vegetais coletados no Ceasa - Campinas, entre os meses de janeiro e fevereiro de 1996. Todas as linhagens isoladas foram testadas quanto à sua capacidade para hidrolisar o óleo de oliva, tendo a linhagem de Rhizopus sp se mostrado altamente eficiente nestes testes preliminares. A linhagem de Rhizopus sp é mantida sob refrigeração em tubos de ensaio contendo meio de batata, dextrose e ágar inclinado e são repicadas, tendo sua pureza verificada, com periodicidade de 3 meses.

$1 \mathrm{~mL}$ de suspensão de esporos, obtida por adição de $5 \mathrm{~mL}$ de água destilada estéril a culturas do microrganismo em tubo de ensaio contendo BDA inclinado e incubado por 72 horas a $30^{\circ} \mathrm{C}$, foi inoculado em frascos erlenmeyer de $500 \mathrm{~mL}$ contendo $20 \mathrm{~g}$ meio de cultura composto por farelo de trigo e água (60:40 em peso). O meio foi mantido a $30^{\circ} \mathrm{C}$ por 120 horas e após este tempo a lipase foi extraída com $100 \mathrm{~mL}$ de água destilada por frasco incubado e precipitada com sulfato de amônio a 70\% de saturação. Ao precipitado foi adicionado um volume de água destilada mínimo para obtenção de uma suspensão que foi dialisada contra água deionizada por 48 horas a $4^{\circ} \mathrm{C}$ e liofilizada para obtenção do "extrato enzimático bruto".

\section{2 - Determinação da atividade lipolítica em dife- rentes substratos}

O meio reacional foi composto de: $1 \mathrm{~g}$ de substrato (óleo de oliva, gordura de coco ou gordura do leite de cabra), $4 \mathrm{~mL}$ de tampão fosfato de sódio ( $\mathrm{pH}=6,0,50 \mathrm{mM})$ e $1 \mathrm{~mL}$ do extrato bruto enzimático (liofilizado e ressuspenso em água na concentração de $10 \mathrm{mg} / \mathrm{mL}$ ). O meio foi mantido a $30^{\circ} \mathrm{C}$ por 60 minutos a $130 \mathrm{rpm}$. A reação foi paralizada pela adição de $15 \mathrm{~mL}$ de acetona/ etanol (1:1 em volume) e a atividade foi medida pela titulação dos ácidos graxos liberados com solução de KOH $50 \mathrm{mM}$ usando fenolftaleina como indicador. Um branco, contendo o mesmo meio reacional que os ensaios e mantido nas mesmas condições de reação, recebeu adição do extrato enzimático bruto apenas após a adição da mistura etanol/acetona e foi titulado da mesma forma que os ensaios para determinação da acidez inicial do substrato empregado. Para o cálculo da atividade enzimática usou-se uma curva padrão de concentração de ácido graxo $\mathrm{x} \mathrm{mL}$ de $\mathrm{KOH} 50 \mathrm{mM}$, sendo o ácido graxo específico para cada substrato, a saber: para o óleo de oliva - ácido oleico; para gordura de coco - ácido láurico e para gordura do leite de cabra: ácido caprílico [6].

Uma unidade de atividade foi definida como a quantidade de enzima necessária para liberar $1 \mu \mathrm{M}$ de ácido graxo por minuto de reação, nas condições do ensaio.

\section{3 - Determinação do teor de proteína}

Para determinação da concentração de proteína nos extratos enzimáticos obtidos (bruto e parcialmente purificado) foi usado o Método de Lowry [8], tendo como padrão albumina de soro bovino.

\section{4 - Determinação do número de saponificação}

A $1 \mathrm{~g}$ de óleo de oliva, gordura de coco ou gordura do leite de cabra foram adicionados $25 \mathrm{~mL}$ de solução de $\mathrm{KOH} 1 \mathrm{M}$ e $4 \mathrm{~mL}$ de tampão acetato de sódio ( $\mathrm{pH}=5,6$, $50 \mathrm{mM}$ ) e mantido em ebulição por 40 minutos. Após este período, a solução de $\mathrm{KOH}$ remanescente foi titulada contra uma solução de $\mathrm{HCl} 1 \mathrm{M}$. O número de saponificação é dado como a quantidade de álcali necessária para saponificar uma quantidade conhecida de amostra e permite estimar a concentração de ácidos graxos de um óleo ou gordura de modo a determinar quanto ácido graxo seria liberado havendo 100\% de hidrólise enzimática.

\section{5 - Caracterização bioquímica do extrato enzimático bruto}

\subsection{1 - Efeito do pH na atividade enzimática}

O meio reacional para este ensaio foi composto de $1 \mathrm{~g}$ de óleo de oliva, $4 \mathrm{~mL}$ de cada tampão descrito a seguir, na concentração de $100 \mathrm{mM}$, e $1 \mathrm{~mL}$ do extrato enzimático bruto a $10 \mathrm{mg} / \mathrm{mL}$. As soluções tampão utilizadas foram: tampão acetato de sódio: $\mathrm{pH}=3,6 ; 4,0 ; 4,5$; 5,0 e 5,6; tampão fosfato de sódio: $\mathrm{pH}=6,0 ; 6,5 ; 7,0 ; 7,5$ e 8,0 e tampão Tris-HCl: $\mathrm{pH}=8.0$; 8,5 e 9,0. O meio foi incubado a $30^{\circ} \mathrm{C}$ por 60 minutos a $130 \mathrm{rpm}$. A reação foi paralisada pela adição de $15 \mathrm{~mL}$ de acetona/etanol (1:1 em volume) e a atividade foi medida pela titulação dos ácidos graxos liberados com solução de KOH 50mM usando fenolftaleína como indicador.

\subsection{2 - Efeito da temperatura na atividade enzi- mática}

O meio reacional foi composto de: $1 \mathrm{~g}$ de óleo de oliva, $4 \mathrm{~mL}$ de tampão fosfato de sódio $(\mathrm{pH}=6,0,0,05 \mathrm{M})$ e $1 \mathrm{~mL}$ do extrato enzimático bruto a $10 \mathrm{mg} / \mathrm{mL}$. O meio foi incubado a diferentes temperaturas, descritas abaixo, por 60 minutos a $130 \mathrm{rpm}$. A reação foi paralisada pela adição de $15 \mathrm{~mL}$ de acetona/etanol (1:1 em volume) e a atividade foi medida pela titulação dos ácidos graxos liberados com solução de $\mathrm{KOH} 50 \mathrm{mM}$ usando fenolftaleina como indicador. As temperaturas testadas foram: 25, 30, $35,40,45,50,55,60$ e $70^{\circ} \mathrm{C}$. 


\subsection{3 - Efeito do pH na estabilidade da enzima}

$1 \mathrm{~mL}$ do extrato enzimático bruto foi tratado com $2 \mathrm{~mL}$ das soluções tampão descritas no item 2.5.1, por 24 horas a $25^{\circ} \mathrm{C}$. Após este periodo, $1 \mathrm{~mL}$ da mistura de reação foi colocado em um meio reacional composto por $1 \mathrm{~g}$ de óleo de oliva e $4 \mathrm{~mL}$ de água destilada para medida da atividade residual, segundo a metodologia já descrita.

\subsection{4 - Efeito da temperatura na estabilidade da enzima}

$2 \mathrm{~mL}$ do extrato enzimático bruto foram incubados a diferentes temperaturas, descritas abaixo, em tampão fosfato $(\mathrm{pH}=6,0,50 \mathrm{mM})$ por 60 minutos. $1 \mathrm{~mL}$ das soluções tratadas foi colocado em meio reacional para medida da atividade residual. As temperaturas utilizadas foram: $20,25,30,35,40,45,50,55,60$ e $70^{\circ} \mathrm{C}$.

\subsection{5 - Efeito da interferência de ions na ativida- de da enzima}

Foram adicionados ao meio reacional, contendo como substrato o óleo de oliva, $\mathrm{CaCl}_{2}$ e $\mathrm{MgSO}_{4}$ nas concentrações de 1 e 10mM no meio, para medida de atividade que foi determinada como anteriormente descrito.

\section{6 - Purificação parcial do extrato enzimático bruto}

$3,5 \mathrm{~g}$ do extrato liofilizado foram dissolvidos em $45 \mathrm{~mL}$ de tampão fosfato $(\mathrm{pH}=6,0 ; 50 \mathrm{mM})$, filtrados em celite para remoção dos esporos presentes e aplicados em coluna de DEAE-SEPHADEX A-50. A resina, previamente tratada com $\mathrm{NaOH} 1 \mathrm{M}$ e com $\mathrm{HCl} 1 \mathrm{M}$, foi estabilizada com tampão fosfato de sódio $(\mathrm{pH}=6,0)$ e usada no empacotamento de uma coluna de vidro de $2,5 \mathrm{~cm}$ x $53 \mathrm{~cm}$. Após a aplicação do extrato enzimático, as proteínas presentes foram eluídas pela adição de $\mathrm{NaCl}$ em gradiente linear entre as concentrações de 100 e $700 \mathrm{mM}$. As frações coletadas em coletor automático foram monitoradas quanto a sua absorção a 280nm (UV) e submetidas à avaliação de atividade contra o substrato $p$-nitrofenil laurato como descrito a seguir. As frações que apresentaram atividade foram concentradas por ultra-filtração, utilizando concentrador adaptado com membranas de $10 \mathrm{KDa}$, sob refrigeração.

\section{7 - Medida de atividade usando substrato $p$ - nitrofenil laurato}

$161 \mathrm{mg}$ de $p$-nitrofenil laurato foram dissolvidos em $190 \mathrm{~mL}$ de tampão acetato $(\mathrm{pH}=5,6 ; 50 \mathrm{mM})$ contendo $2,1 \%$ de Triton X-100. A mistura foi homogeneizada a $70^{\circ} \mathrm{C}$ até a completa dissolução do substrato. Uma alíquota de $0,95 \mathrm{~mL}$ desta mistura de reação foi incubada a $37^{\circ} \mathrm{C}$ por 15 minutos e adicionada de $50 \mu \mathrm{L}$ da solução em teste, permanecendo nas condições de ensaio por 15 minutos. A reação foi paralisada pela adição de $2 \mathrm{~mL}$ de acetona. Ao branco foi adicionada solução enzimática apenas após a paralisação da reação. A liberação do $p$-nitrofenol pela ação da lipase gera coloração amarelada que pode ser quantificada por absorção a 410nm em comparação com uma curva padrão.
Uma unidade de atividade foi definida como a quantidade de enzima necessária para liberar $1 \mu \mathrm{M}$ de $p$-nitrofenol por minuto de reação, nas condições do ensaio.

\section{8 - Caracterização bioquímica do extrato enzimático parcialmente purificado}

Foi conduzida nas mesmas condições usadas para o extrato enzimático bruto, sendo o substrato utilizado o $p$-nitrofenil laurato. Além disso, foi ainda estudado o efeito da concentração de substrato $(0,5 ; 1,0 ; 2,0 ; 3,0 ; 4,0$; $5,0 ; 10,0 \mathrm{mM})$ na atividade enzimática possibilitando a determinação da Constante de Michaelis-Menten $\left(\mathrm{K}_{\mathrm{m}}\right)$ e da Velocidade Máxima de reação $\left(\mathrm{V}_{\text {máx }}\right)$ pelo sistema gráfico de Lineweaver \& Burk.

\section{3 -RESULTADOS E DISCUSSÃO}

\section{1 - Produção da enzima}

Foi produzido $1 \mathrm{~g}$ de extrato enzimático bruto liofilizado para cada $72 \mathrm{~g}$ de farelo de trigo, nas condições descritas. Este extrato foi obtido de um caldo de cultura com atividade igual a $1157 \mathrm{U} / \mathrm{mL}$. HIOL et al. [5] obtiveram $120 \mathrm{U} / \mathrm{mL}$ de atividade lipolitica em cultivos otimizados de Rhizopus oryzae em meio liquido de cultivo. Em vista disto, o rendimento obtido, em termos de atividade, foi considerado bastante satisfatório.

\section{2 - Purificação parcial em coluna de DEAE-Sephadex}

Foram encontradas duas frações com atividade lipolítica: a fração I foi eluída com $200 \mathrm{mM}$ de $\mathrm{NaCl}$ e a fração II com $300 \mathrm{mM}$ de acordo com o gradiente utilizado (Figura 1).

Os resultados obtidos no processo de purificação parcial estão sumarizados na Tabela 2.

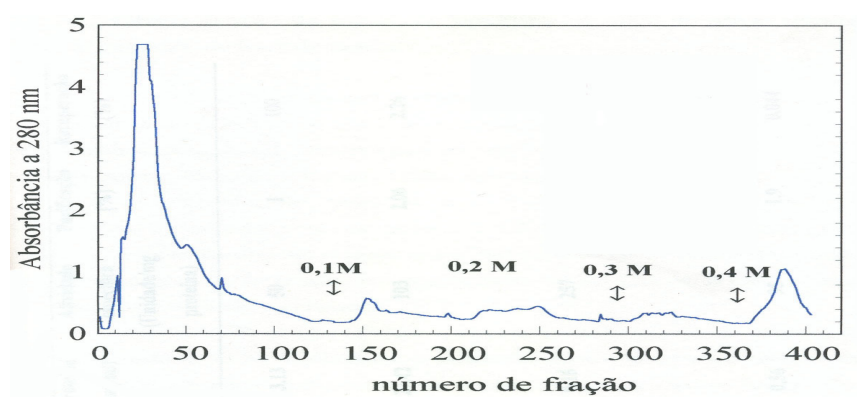

FIGURA 1. Cromatograma obtido para lipase de Rhizopus sp em coluna de DEAE-Sephadex, A-50.

Os resultados obtidos chamam atenção pelos baixos valores obtidos para fator de purificação e porcentagem de recuperação. Isto se dá devido a grande perda de atividade sofrida pela lipase durante a etapa de purificação por cromatografia de troca iônica. Acredita-se que esta perda se deva ao fato de serem as lipases, em sua grande maioria, glicoproteinas que sofrem perda de seu componente não protéico durante a corrida cromatográfi- 
ca [1]. Esta metodologia de purificação, no entanto, se mostra útil e válida, por seu baixo custo e facilidade de aplicação, quando se trata de obter uma pequena concentração da enzima parcialmente purificada para melhor estudar suas características bioquímicas e seu comportamento catalítico.

TABELA 2. Purificação parcial da lipase de Rhizopus sp.

\begin{tabular}{|c|c|c|c|c|c|c|c|}
\hline Etapa & $\begin{array}{l}\text { Vol. } \\
\text { (mL) }\end{array}$ & $\begin{array}{l}\text { Atividade } \\
\text { (IL/mL) }\end{array}$ & $\begin{array}{l}\text { Ativid ad e } \\
\text { Total (U) }\end{array}$ & $\begin{array}{l}\text { Protéína } \\
(\mathbf{m g} / \mathbf{m L})\end{array}$ & $\begin{array}{c}\text { A tividad e } \\
\text { equecifica } \\
\text { (U/mg) }\end{array}$ & $\begin{array}{c}\text { Fator de } \\
\text { Purificação }\end{array}$ & $\begin{array}{c}\text { Recupeação } \\
(0 \%)\end{array}$ \\
\hline $\begin{array}{l}\text { Sobrenad ante do } \\
\text { meio de cultura }\end{array}$ & 5170 & 1157 & 5981690 & 23,13 & 50 & 1 & 100 \\
\hline $\begin{array}{c}\text { Fracion amento } \\
\text { com sulfato de } \\
\text { amônio }\end{array}$ & 48 & 2825 & 135600 & 27,42 & 103 & 2,06 & 2,26 \\
\hline $\begin{array}{c}\text { Cromatngrafia } \\
\text { em coluna de } \\
\text { DE.AE-Seph hdex } \\
\text { - fraçãoI }\end{array}$ & 50 & 41,13 & 2056,5 & 0,16 & 257 & 5,14 & 0,034 \\
\hline $\begin{array}{l}\text { Cromatografia } \\
\text { em conluna de } \\
\text { DE.AE-Seph adex - } \\
\text { fraçãoII }\end{array}$ & 50 & 53,13 & 2656,5 & 0,56 & 95 & 1,9 & 0,044 \\
\hline
\end{tabular}

\section{3 - Atividade sobre diferentes substratos}

A lipase bruta de Rhizopus sp apresentou maior atividade hidrolitica sobre a gordura de coco, como pode ser observado na Figura 2, hidrolizando até 95\% deste substrato em 60 minutos. Isto indica boa afinidade por ácidos graxos saturados de cadeia média, como o ácido láurico (12:0).

Estudos sobre uma linhagem de Aspergillus flavus realizados por HOOVER et al. [6] mostraram que a lipase produzida pela linhagem hidrolisou preferencialmente triglicerídeos compostos pos ácidos graxos de cadeia média, apresentando valor de $\mathrm{K}_{\mathrm{m}}$ de $9,09 \times 10^{-4} \mathrm{mM}$ para trilaurina e de $1,42 \times 10^{-3} \mathrm{mM}$ para trimiristina.

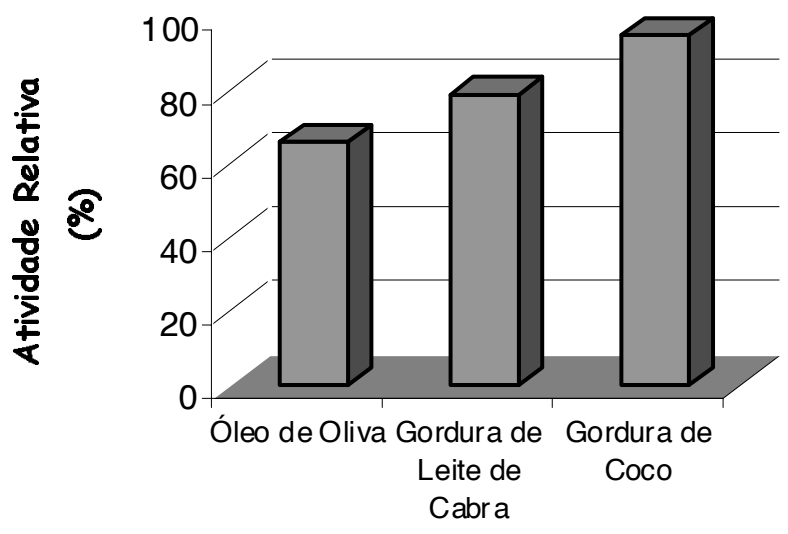

Substratos

FIGURA 2. Ação hidrolítica do extrato enzimático bruto sobre diferentes substratos.

\section{4 - Efeito do pH na atividade enzimática}

Nas condições estudadas a lipase de Rhizopus sp em extrato bruto apresentou maior atividade na faixa de $\mathrm{pH}$ entre 6,0 e 6,5 como pode ser observado na Figura 3.

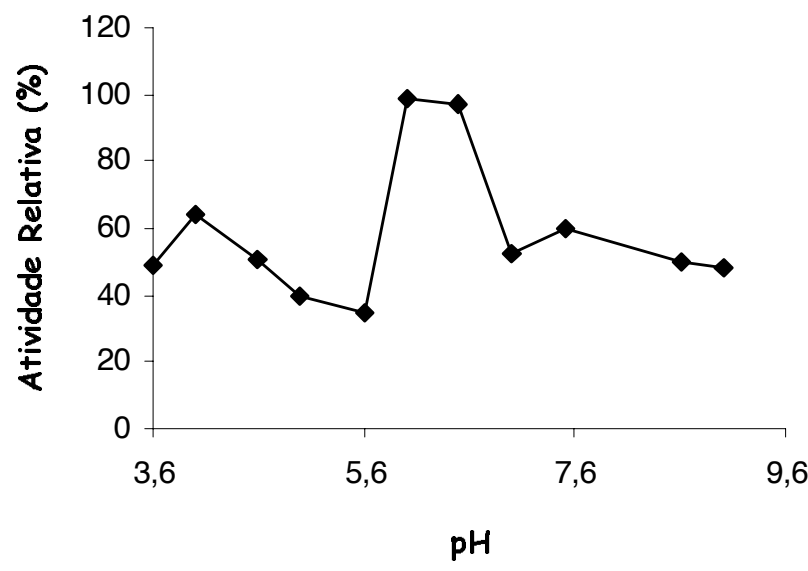

FIGURA 3. Efeito do pH na atividade do extrato enzimático bruto.

Entre as frações purificadas a fração II se comportou de modo muito semelhante ao extrato bruto, tendo maior atividade a $\mathrm{pH} 6,5$, enquanto que a fração I apresentou valor de $\mathrm{pH}$ ótimo em torno de 7,5.

De acordo com dados obtidos por IWAI e TSUJISAKA [8], os valores de $\mathrm{pH}$ ótimos para as três diferentes frações lipoliticas de Rhizopus delemar foram de 5,6 para a lipase A e 5,5 para as lipases B e C.

\section{5 - Efeito da temperatura na atividade enzimática}

A temperatura ótima para a lipase bruta estudada nas condições do experimento está ao redor de $40^{\circ} \mathrm{C}$, mantendo $50 \%$ ou mais de sua atividade entre 40 e $55^{\circ} \mathrm{C}$ (Figura 4). Para a fração purificada I a temperatura ótima de hidrólise foi de $40^{\circ} \mathrm{C}$, enquanto a fração II apresentou maior atividade a $38^{\circ} \mathrm{C}$.

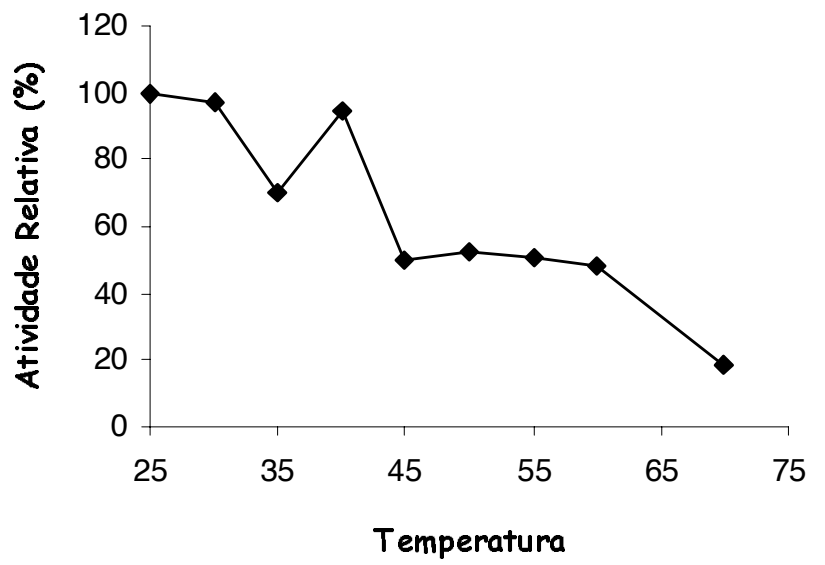

FIGURA 4. Efeito da temperatura na atividade do extrato bruto enzimático. 
HAAS et al. [4] encontraram uma atividade de $80 \%$ entre as temperaturas de $25^{\circ} \mathrm{C}$ e $38^{\circ} \mathrm{C}$ para a lipase de Rhizopus delemar, ocorrendo máximo de atividade a $30^{\circ} \mathrm{C}$ e nenhuma atividade acima de $45^{\circ} \mathrm{C}$.

\subsection{Efeito do pH na estabilidade da enzima}

A lipase bruta de Rhizopus sp se mostrou mais estável na faixa de valores de $\mathrm{pH}$ entre 5,6 e 8,0, como pode ser observado na Figura 5.

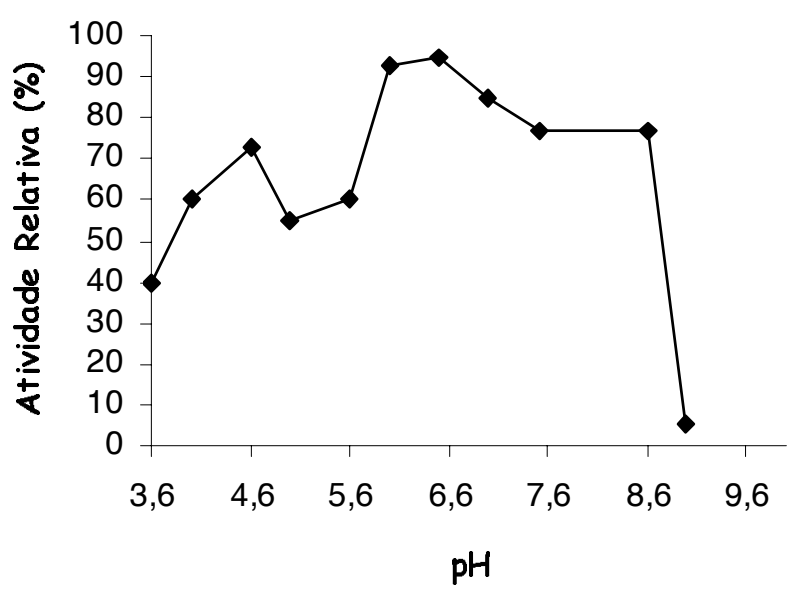

FIGURA 5. Efeito do $\mathrm{pH}$ na estabilidade do extrato bruto enzimático.

A fração I teve maior atividade residual após tratamento entre pH 3,6 e 5,6 e a fração II entre 6,0 e 7,5.

IWAI e TSUJISAKA [7] em seu trabalho sobre três frações lipoliticas de Rhizopus delemar verificaram que a lipase A foi mais estável entre os valores de $\mathrm{pH}$ de 3,0 a 8,0 , enquanto que as lipases $\mathrm{B}$ e $\mathrm{C}$ apresentaram maior estabilidade entre 4,0 e 7,0.

\section{7 - Efeito da temperatura na estabilidade da enzima}

O extrato enzimático bruto permaneceu estável na faixa de temperatura entre 40 e $55^{\circ} \mathrm{C}$, mantendo uma atividade relativa superior a $70 \%$ (Figura 6).

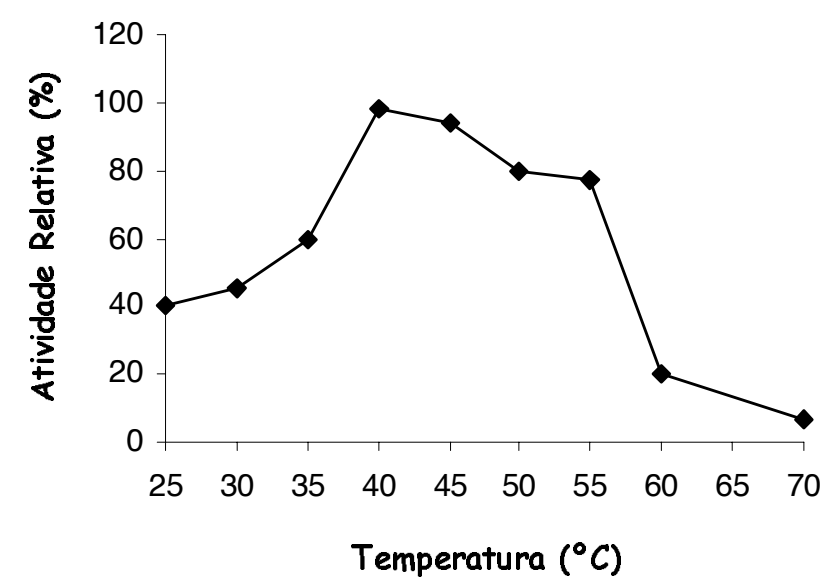

FIGURA 6. Efeito da temperatura na estabilidade do extrato bruto enzimático.
As frações obtidas se comportaram de forma semelhante entre si, permanecendo estáveis entre 20 e $40^{\circ} \mathrm{C}$ nas condições do ensaio, mantendo atividade relativa de 80 e $85 \%$ respectivamente.

As lipases de Aspergillus niger, Rhizopus delemar, Geotrichum candidum e Penicillium cyclopium apresentaram estabilidade térmica, em pH 5,6, iguais a $50^{\circ} \mathrm{C}, 65^{\circ} \mathrm{C}$, $45^{\circ} \mathrm{C}$ e $40^{\circ} \mathrm{C}$; respectivamente, segundo TSUJISAKA et al. [15].

\section{8 - Efeito da adição de íons ao meio reacional}

Conforme pode ser observado na Figura 7, a adição de ions $\mathrm{Ca}^{++}$aumenta significativamente a atividade hidrolitica do extrato enzimático bruto de Rhizopus sp sobre o substrato óleo de oliva.

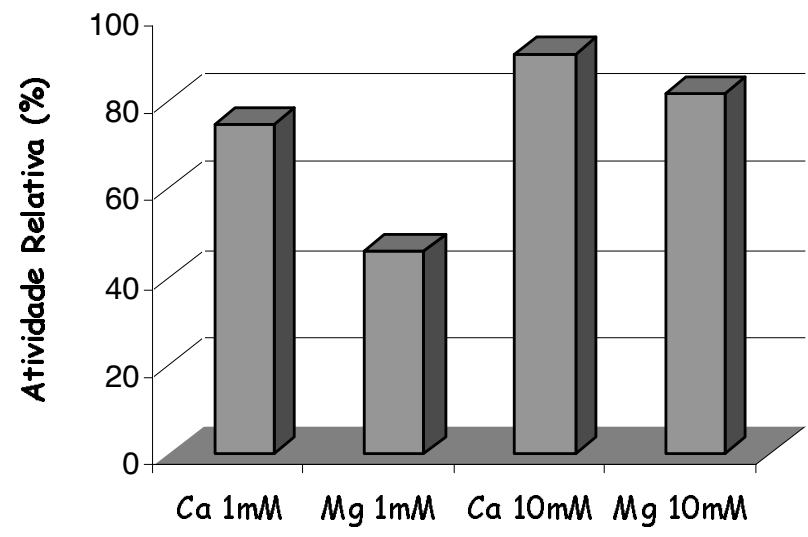

FIGURA 7. Efeito da adiçăo de íons ao meio reacional.

SUZUKI et al. [14] em estudos com lipase de Rhizopus japonicus não observaram alterações na atividade lipolítica após adição de $1 \mathrm{mM}$ de diversos íons metálicos e de sais biliares.

\section{9 - Efeito da concentração de substrato na ativida- de da enzima}

Para a fração purificada I foram obtidos os valores $5,5 \times 10^{-2} \mathrm{mM}$ de $p$-nitrofenil laurato para $\mathrm{K}_{\mathrm{m}}$ e $1,99 \mu \mathrm{M}$ de $p$ - nitrofenol/min/mg de enzima para $\mathrm{V}_{\text {máx }}$, de acordo com o sistema gráfico de Lineweaver \& Burk utilizado.

Para a fração II, nas mesmas condições de experimento os valores encontrados foram de $7,6_{x} 10^{-2} \mu \mathrm{M}$ de $p$-nitrofenil laurato para $\mathrm{K}_{\mathrm{m}}$ e de $1,19 \mu \mathrm{M}$ de $p$ - nitrofenol/ $\mathrm{min} / \mathrm{mg}$ de enzima para $\mathrm{V}_{\text {máx }}$.

\section{4 - CONCLUSÕES}

De acordo com os resultados pode-se concluir que:

- O caldo de cultura produzido, após a extração da enzima bruta com água destilada, apresentou uma atividade de $1157 \mathrm{U} / \mathrm{mL}$, considerada alta em comparação com alguns dados da literatura consultada, para produção em meio líquido. 
- O extrato enzimático bruto apresentou condições ótimas de atividade a $40^{\circ} \mathrm{C}$ em valores de $\mathrm{pH}$ entre 6,0 e 6,5. Demonstrou estabilidade ao $\mathrm{pH}$ na faixa entre 5,6 e 8,0 e à temperatura entre $40^{\circ} \mathrm{C}$ e $55^{\circ} \mathrm{C}$. A atividade apresentou redução de $87 \%$ quando submetida a tratamento à temperatura de $70^{\circ} \mathrm{C}$ durante 60 minutos.

- O extrato bruto enzimático apresentou maiores valores de hidrólise para gordura de coco em comparação com os outros substratos, nas condições do ensaio.

- A utilização de íons de cálcio contribuiu significativamente para o aumento da atividade hidrolitica do extrato bruto sobre o substrato óleo de oliva.

- As frações I e II, obtidas após purificação parcial do extrato bruto, apresentaram características bioquimicas semelhantes ao extrato bruto para o substrato $p$-nitrofenil laurato .

- Os valores de $\mathrm{K}_{\mathrm{m}}$ foram $5,5 \times 10^{-2} \mu \mathrm{M}$ de $p$-nitrofenil laurato para a fração I e $7,6 \times 10^{-2} \mu \mathrm{M}$ de $p$-nitrofenil laurato para a fração II.

- Os valores de $\mathrm{V}_{\text {máx }}$ foram $1,99 \mu \mathrm{M}$ de $p$ - nitrofenol/ $\mathrm{min} / \mathrm{mg}$ de enzima para a fração I e $1,19 \mu \mathrm{M}$ de p- nitrofenol/min/mg de enzima para a fração II.

- O uso de cromatografia de troca iônica para purificação da lipase produzida pela nova linhagem de Rhizopus sp. não parece ser aconselhável, uma vez que a perda de atividade devida à etapa de purificação foi bastante significativa.

\section{5 - REFERÊNCIAS}

[1] BORGSTON, B.; BROCKMAN, H.L. Lipases. Elsevier. Amsterdam. 1984.

[2] CAstro, H.F.; Anderson, W.A. Fine chemicals by biotransformation using lipases. Química Nova, v.18, n.6, p.544-554, 1995.

[3] GANDHI, N.N. Applications of lipases. Journal of the American Oil Chemists Society, v.74, n.6, p. 621-634, 1997.
[4] HAAS, M.J.; CICHOWICZ, D.J.; BAILEY, D.G. Purification and characterization of an extracelular lipase from the Rhizopus delemar. Lipids, v.27, n.8, p.571-576, 1992.

[5] HIOL, A et al. Purification and characterization of an extracellular lipase from a thermophilic Rhizopus oryzae strani isolated from palm fruit. Enzyme and Microbial Technology, v.26, p.421-430, 2000.

[6] HOOVER, R.; LAURENTIUS, S.F., GUNETILEK, K.G. Spoilage of coconut oil. Purification and properties of fungal lipase that attacs coconut oil. Journal of American Oil Chemists Society, v.50, n.3, p.64-67, 1973.

[7] IWAI, M. TSUJISAKA, Y. The purification and the properties of three kinds of lipases from Rhizopus delemar. Agricultural and Biological Chemistry, v.38, n.6, p. 1241-1247, 1974.

[8] LOWRY, O.H.; ROSEBROUGH, A.L.F.; RANDALL, R.F. Protein measurement with the Folin-phenol reagent. Journal of Biological Chemistry, v. 193, p. 265-275. 1951.

[9] MACEDO, G.A.; PASTORE, G.M. Síntese de ésters de aroma por lipases microbianas em meio livre de solvente orgânico. Campinas, 1997. 143p. Exame de qualificação (Doutor em Ciência dos Alimentos) - Faculdade de Engenharia de Alimentos, Universidade Estadual de Campinas (UNICAMP).

[10] MACRAE, A.R.; HAMMOND, R.D. Present and future applications of lipases. Biotechnology and Genetic Engeneering Reviews, v.3, p. 193-217, 1985.

[11] MUKESH, D.; JADHAV, S.; BEVINAKATTI, H.S. Lipasecatalysed esterification reactions. Experimental and modelling studies. Journal of Chemical Technology and Biotechnology, v.69, n.2, p.179-183, 1997.

[12] PARK, Y.K.; PASTORE, G.M.; ALMEIDA, M.M. Hydrolysis of soybean oil by a combinated lipase system. . Journal of American Oil Chemists Society, v.65, n.2, p.252254, 1988.

[13] PASTORE, G.M.; MACEDO, G.A.; PARK, Y.K. Partial purification and characterization of an extracelular lipase from a newly isolated strain of Geotrichum $s p$. Revista de Microbiologia, v.28, p.90-95, 1997.

[14] SUZUKI, M.; YAMAMOTO, H.; MIZUGAKI, M. Purification and general properties of a metal-insensitive lipase from Rhizopus javanicus NR400. Journal of Biochemistry, n. 100, p.1207-1213, 1986.

[15] TSUJISAKA, Y.; IWAI, M.; TOMINAGA, Y. A comparative study on some properties of fungal lipase. Proceedings of the IV International Fermentation Symposium, p. 315-320, 1972. 